\title{
Шонгуйские дислокации в структуре основных сейсмогенных зон Кольского региона: проявления, тектоническая позиция, возраст
}

\author{
Николаева С.Б. ${ }^{1}$, Шварев С.В. ${ }^{2,4}$, Родкин М.В. ${ }^{3}$, Королева А.О. ${ }^{4}$ \\ ${ }^{1}$ Геологический институт КНЦ РАН, Anamumbl,nikolaeva@geoksc.apatity.ru \\ ${ }^{2}$ Институт географии РАН, Москва, shvarev@igras.ru \\ ${ }^{3}$ Институт теории прогноза землетрясений и математической геофизики PAH, Москва, rodkin@тіtp.ru \\ ${ }^{4}$ Институт физики Земли им. О.Ю. Шмидта РАН, Москва, alyaska@yandex.ru
}

Аннотация. Представлены новые результаты сейсмогеологических исследований на севере Кольского региона. Детальное изучение разных типов сейсмодислокаций на ключевом участке близи поселка Шонгуй, позволили уточнить структурную позицию очаговой области палеоземлетрясений, собрать сведения о трещиноватости пород и кинематике блоков для геодинамических реконструкций, определить параметры палеоземлетрясений. Установлено, что комплекс дислокаций сопряжен с крупной субмеридиональной морфоструктурной зоной высшего порядка, в которой в конце позднеледниковья и в голоцене неоднократно происходили сильные землетрясения.

Ключевые слова: палеосейсмодислокации, землетрясения, сейсмогенная зона, Кольский регион, Фенноскандинавский щит.

\section{Shonguy dislocations in the structure of major seismogenic zones of the Kola Region: occurrences, tectonic position, age}

\author{
Nikolaeva S.B. ${ }^{1}$, Shvarev S.V. ${ }^{2,4}$, Rodkin M.V. ${ }^{3}$, Koroleva A.O. ${ }^{4}$ \\ ${ }^{1}$ Geological Institute of Kola Science Center RAS, Apatity,nikolaeva@geoksc.apatity.ru \\ ${ }^{2}$ Institute of Geography RAS, Moscow,shvarev@igras.ru \\ ${ }^{3}$ International Institute of Earthquake Prediction Theory and Mathematical Geophysics RAS, Moscow, \\ rodkin@mitp.ru \\ ${ }^{4}$ Schmidt Institute of Physics of the Earth of RAS, Moscow, alyaska@yandex.ru
}

\begin{abstract}
The paper presents new results of seismogeological studies in the northern Kola Region. Various types of seismic dislocations near the Shonguy settlement have been thoroughly studied, which allows to specify parameters of possible seismic sources specify the structural position of the focus and collect information on the kinematics of seismogenic blocks. It has been found that the Shongui dislocations are associated with a large morphostructural zone of higher order where strong earthquakes occurred repeatedly at the end of the Late Glacial and during the Holocene.

Key words: paleoseismic dislocations, earthquakes, seismogenic zone, Kola Peninsula, Fennoscandian Shield.
\end{abstract}

\section{Введение}

На протяжении последних десятилетий в региональной геологии выдвинут ряд принципиально важных положений, позволяющих по новому подойти к проблеме тектонической активности и сейсмичности платформенных (щитовых) территорий. Трудами разных исследователей, как в России, так и за рубежом собрано множество свидетельств о следах сильных древних землетрясений в Фенноскандии (Lukashov, 1995, Николаева, 2001, 2013, Morner, 2003, Kukkonen et al., 2010, Родкин и др., 2012, и др.). При этом сама проблема позднеледниковой и голоценовой сейсмичности остается дискуссионной как по вопросам генезиса, так и параметризации палеоземлетрясений.

В настоящем сообщении представлены результаты сейсмогеологических исследований на ключевом участке близи поселка Шонгуй (Кольский регион). Исследования осуществлялись с помощью палеосейсмогеологического метода (McCalpin, 2009) и с применением новых подходов для определения параметров палеоземлетрясений, разработанных специально Фенноскандинавского щита (Родкин и др., 2012). Детальное изучение разных типов сейсмодислокаций позволили уточнить структурную позицию очаговой области палеоземлетрясений, собрать сведения о трещиноватости пород и кинематике блоков, определить интенсивность и возраст событий. 


\section{Геолого-структурное положение}

Участок исследований входит в состав Центрально-Кольского геоблока, сложенного в основном позднеархейскими гнейсами и гранито-гнейсами и находится вне основных долгоживущих разломных зон Кольского региона (рис. 1 a, б). Главными древними структурообразующими элементами территории являются разломы северо-западной ориентировки (рис. 1 в). Однако, согласно материалам дешифрирования дистанционных данных, существенную роль играют и нарушения СВ и ССЗ румбов, обладающие наложенным характером, и, очевидно, более молодым возрастом.

В структуре основных сейсмогенных зон Кольского региона Шонгуйские дислокации приурочены к крупной субмеридиональной морфоструктурной зоне высшего порядка - ЦентральноКольской, где фиксируются системы преимущественно сдвиговых нарушений ССЗ ориентировки (Никонов и др., 2019) (рис. 1 г). Эта зона отделяет собственно Кольский полуостров от материковой части и является швом, восточнее и западнее которого существенно отличаются как элементы тектонического рельефа, так и характер экзогенных процессов (Shvarev, 2018). В отличие от восточного фланга зоны, четко проявляющегося системой эшелонированных разломов (Геодинамическая..., 1991), по-видимому, с существенной сдвиговой составляющей, западный фланг зоны, где находится участок сейсмотектонических нарушений, структурно более неоднородный (рис. 1 д).

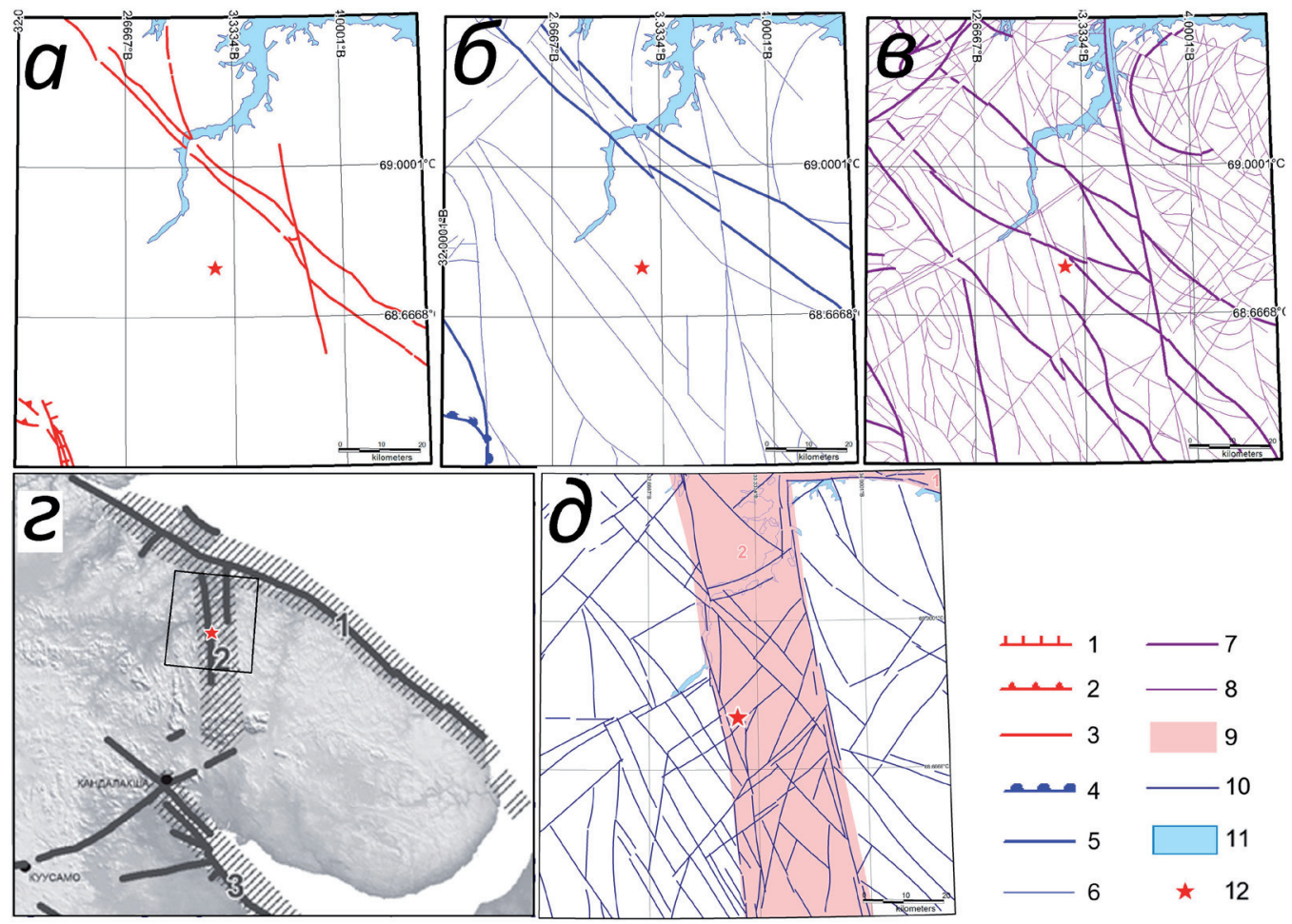

Рис. 1. Структурно-тектоническое положение Шонгуйских дислокаций

Разломы: а) 1 - сбросы, 2 - надвиги, 3 - с неопределенной кинематикой, по (Геологическая..., 2001); б) 4-5 - главные: 4 - надвиги, 5 - с неопределенной кинематикой, 6 - второстепенные, по (Государственная..., 2000); в) 7 - главные, 8 - второстепенные, по (Геодинамическая..., 1991); г) Палеосейсмогенные зоны: 1 - Мурманская, 2 - Центрально-Кольская, 3 - Кандалакшская, по (Никонов и др., 2019); д) Линеаменты, выделенные по материалам дешифрирования космических снимков и ЦМР: 9 - сейсмогенная зона, 10 - прочие линеаменты, 12 - элементы гидрографии, 13 - положение участка исследований.

Fig. 1. Structural position of the Shongui dislocations.

Faults: a) 1 - normal faults, 2 - thrusts, 3 - with unknown parameters (after Geological ..., 2001); b) 4-5 - main: 4 - thrusts, 5 - with unknown parameters, 6 - secondary (after State ..., 2000); c) 7 - major, 8 - secondary (after Geodynamic ..., 1991). d) Paleoseismic zones: 1 - Murmansk, 2 - Central Kola, 3 - Kandalaksha (after Nikonov et al., 2019). e) Lineaments, based on the interpretation of satellite images and DEM: 9 - seismogenic zone, 10 - other lineaments, 11 - hydrographic elements, 12 - location of the study area. 


\section{Результаты исследований}

Необычное раздробление скальных выходов докембрийских пород на участке у пос. Шонгуй впервые было замечено еще в 90-х годах прошлого столетия сотрудниками ГИ КНЦ РАН. Морфологические особенности нарушений с признаками импульсного образования и сосредоточение их на определенной площади позволило позднее рассматривать эти дислокации как эпицентральную область древних землетрясений (Nikolaeva, 2008). С тех пор участок не исследовался. Изучение Шонгуйских дислокаций возобновилось авторами настоящего сообщения в 2018 г.

Морфология участка характеризуется структурно-денудационным рельефом, высотные отметки которого не превышают 220-240 м и только к востоку от него массивы гор поднимаются выше 400-450 м над у.м. Дислокации развиты в скальных выходах гранито-гнейсов, сохранивших следы ледниковой экзарации и физического выветривания. На этом фоне отчетливо выделяется зона деструкции: расколотые ортогональными системами трещин скальные массивы-останцы, участки дробления и повышенной трещиноватости пород, крупноглыбовые обвалы, явления отрыва и горизонтального смещения скальных фрагментов от уступов, блоки отседания от склонов (рис. 2). Они образуют закономерный парагенезис сейсмотектонических, сейсмогравитационных и сейсмовибрационных нарушений, которые тесно сопряжены и коррелируют друг с другом.

Здесь мы сосредоточимся на характеристике наиболее характерного элемента зоны деструкции - скального останца $300 \times 300 \mathrm{M}$, обрамленного отвесными уступами высотой от 1.5 до $8-10$ м. Поверхность останца плоская, на флангах (вблизи уступов) местами ступенчатая, практически лишена обломочного материала. Вертикальные трещины, ровные, уходящие на глубину более 5м, нарушающие поверхность массива, имеют ширину зияния 0.2-0.5м (рис. 2 a). Краевые части уступов, ограничивающих массив, расколоты (рис. 2б,в), а в основании уступов развиты неравномерно распределенные остроугольные глыбовые обвалы и вывалы - от полного отсутствия, до шлейфа в 20-30 м шириной, с отдельными глыбами, отброшенными и дальше. Отброс глыб от уступов, как показали расчеты, в 1.1-1.9 раз превышает высоту обвальной стенки и свидетельствует о дополнительном (сейсмическом) импульсе.

Морфоструктура останца определяется трещинами и разрывами ССЗ и ВСВ направлений при существенно меньшей роли СВ и ССВ простираний. Эти направления согласуются с выделенными при дешифрировании основными структурообразующими элементами территории (рис. 1 д). Ведущее морфоструктурное направление - СС3, которое в большей степени проявляется во внешнем облике массива. Это же направление является основным и в распределении латеральных смещений глыбового материала по периферии массива. При этом четко выделяется максимум в ЮЮВ направлении, что свидетельствует о прохождении сейсмической волны с севера на юг. Аналогичные смещения характерны и для крыльев трещин в массиве, что в совокупности указывает на сдвиговый характер сейсмогенерирующих смещений вдоль зоны СС3 простирания.

Детальное изучение этого комплекса дислокаций показало, что все они отличаются от нарушений, образованных морозным выветриванием, денудацией или крипом. Несогласованность направления блоковых смещений с направлением движения ледника исключает и водно-ледниковое воздействие. Явления отрыва и смещения отдельных блоков, как в латеральном, так и в вертикальном направлениях, могли возникнуть исключительно при импульсных, моментальных воздействиях.

Изучение направлений блоковых смещений глыбового материала. В пределах останца и по его периферии были произведены замеры и проанализирован 151 случай смещений глыб на субгоризонтальных поверхностях. Смещения отдельных скальных блоков можно описать как следствие получения ими импульса скорости. В смещениях глыб в пределах массива (49 случаев) абсолютное преобладание имеет направление С-Ю (70 \%), а по периферии массива (121 случай), обнаруживается преобладание двух систем с азимутами смещений в интервалах $305-5^{\circ}$ и $160-220^{\circ}$ и $250-280^{\circ}$. Следует отметить, что именно четкие максимумы азимутов с противоположно направленными смещениями характерны для очаговых зон землетрясений. На данном этапе исследований, пока предположительно, можно отнести наблюденные смещения к двум эпизодам сейсмогенных воздействий.

Возраст. Соотношение форм рельефа и палеогеографические реконструкции на объекте и вокруг него позволили сделать вывод об образовании Шонгуйских сейсмодислокаций в результате не- 

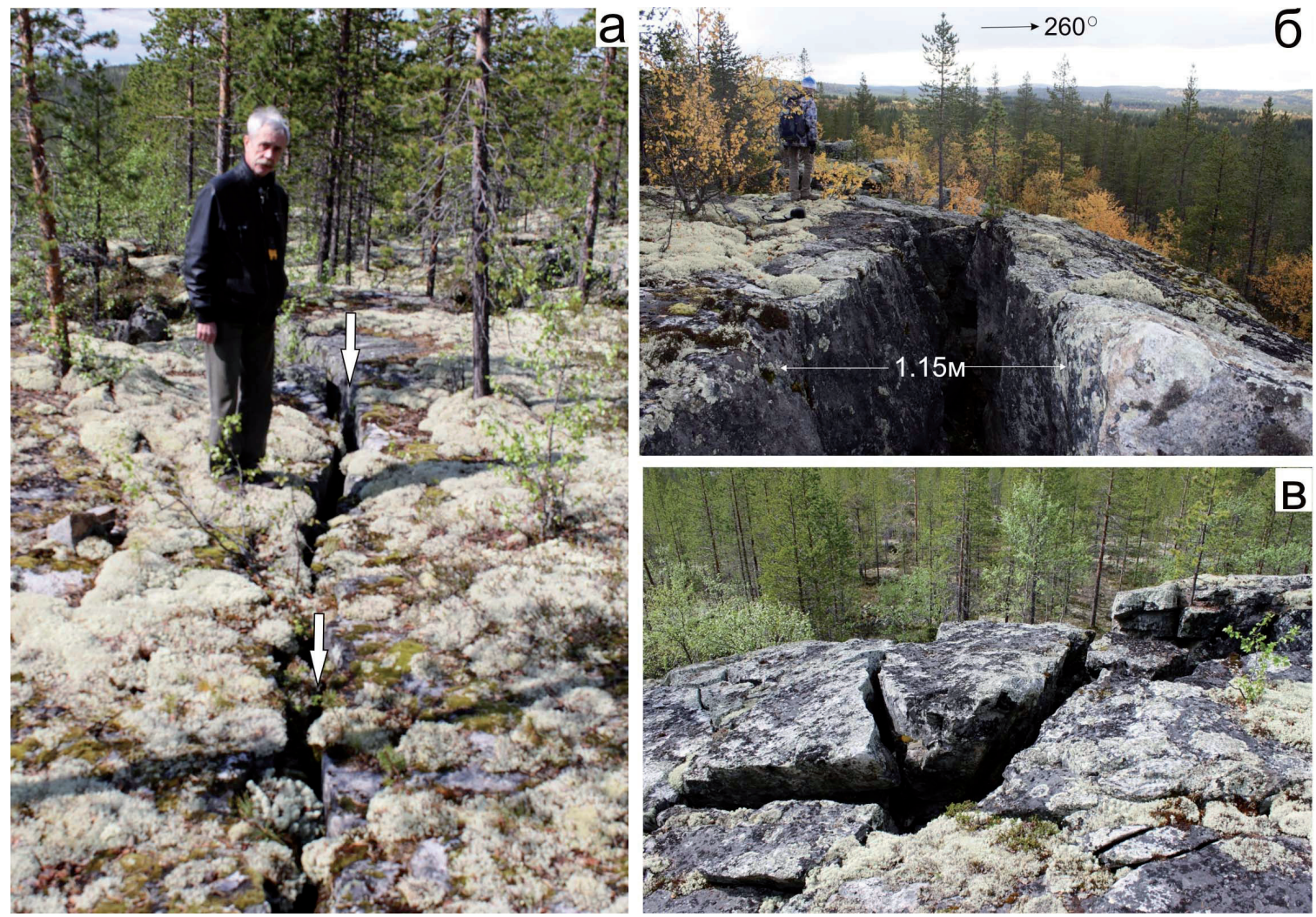

Рис. 2. Сейсмические проявления в гранито-гнейсах Шонгуйских дислокаций.

a - трещины на поверхности массива; б, в - бровка западного уступа с расколами и дроблением (фото С.Б. Николаевой).

Fig. 2. Seismic phenomena in granite-gneisses of the Shongui dislocations.

$\mathrm{a}$ - cracks on the surface of the massif; b, c-edge of the western scarp with splits and crushing, (photo by S.B. Nikolaeva).

скольких событий. К настоящему времени определенно устанавливается только два из них. Самое ранее событие соотносится с явлениями разжижения (ликвефакции) и хрупких деформаций (разрывов и микродаек), обнаруженных в тонкослоистых песках и супесях, слагающих 47-метровую террасу в долине реки Кола (Николаева, 2013). Судя по результатам спорово-пыльцевых и диатомовых анализов, образование этих отложений происходило в позднем дриасе (Никонов, 1964). С этими же возрастными оценками согласуется время схода оползня морены со склона под Мурманском $\geq 10000$ л.н. (Nikolaeva, 2008).

Более позднее событие определено по калиброванным радиоуглеродным анализам двух образцов почвенно-торфяных слоев, перекрытых скальными глыбами, развитыми в основании уступов останца. Оба образца показали возраст в интервале 192-313 лет назад. Полученные даты отражают время формирования органического материала, захороненного под глыбовыми обвалами, и отвечают нижнему возрастному пределу образования самих глыбовых навалов. При этом наблюдается хорошая корреляция этого возрастного интервала со временем исторического VI-ти балльного землетрясения, которые пережили жители пос. Кола 18 (7 по старому стилю) февраля 1772 года (Мушкетов, Орлов, 1893). Не исключено, что отдельные глыбовые навалы (блоки с неустойчивым положением) и повторное дробление пород могли возникнуть при V-VI-ти бальных сотрясениях этого исторического события, однако основные разрушения массива с латерально перемещенными на несколько метров и запрокинутыми глыбами до 8 м в поперечнике, свидетельствуют о более сильном и более раннем землетрясении.

Типы, масштаб, величины смещенных блоков, а также существующие сейсмологические шкалы (Michetti et al., 2007) позволяют предварительно оценивать силу позднеледникового события на участке не менее чем IX баллов по шкале MSK-64, сила более слабого и более молодого события предварительно оценивается в VI-VII баллов. 


\section{Выводы}

1. На севере Кольского региона выявлена очаговая область палеоземлетрясений, представленная различными типами дислокаций (сейсмотектоническими, сейсмогравитационными, сейсмовибрационными).

2. Ведущим морфоструктурным направлением является СС3 при существенно меньшей роли $\mathrm{CB}$ и ССВ простираний. Установлен сдвиговый характер сейсмогенерирующих смещений вдоль зоны ССЗ простирания.

3. Определен возраст двух сейсмических событий с разной интенсивностью и направленностью импульсов: позднеледниковое-раннеголоценовое с I $\geq$ IX баллов и позднеголоценовое с возрастом около 192-313 л.н. с I = VI-VII баллов.

Дальнейшие исследования будут направлены как на уточнение возраста палеоземлетрясений, так и их магнитуды и интенсивности, что возможно, со временем, позволит подойти к вопросу об их периодичности и будет способствовать корректировке карт ОСР Российской Федерации.

Работа выполнена в рамках госзаданий по темам НИР ГИ КНЦ РАН № 0226-2019-0054, ИГ РАН № 0148-2019-0005 и № 0144-2014-00097 ИФЗ им О.Ю. Шмидта РАН.

\section{Литература}

1. Геодинамическая карта Кольского полуострова. М-б 1:500000 (ред. Е.Я. Шенкман). Мингео СССР. НПО «Аэрогеология». МОМКАГЭ. 1991.7 л.

2. Геологическая карта Кольского региона. Масштаб 1:1000000 (под ред. Митрофанова Ф.П.). Апатиты. Изд-во: КНЦ РАН. 2001. 1 л.

3. Государственная геологическая карта Российской федерации (новая серия). М-б 1:1000000. Лист R-(35)-37 (Мурманск). СПб., ВСЕГЕИ. 2000.

4. Мушкетов И.В., Орлов А.П. Каталог землетрясений Российской империи. Типография Императорской академии наук. Санкт-Петербург. 1893. T. XXIV. 582 с.

5. Николаева С.Б. Палеосейсмические проявления в северо-восточной части Балтийского щита и их геолого-тектоническая позиция // Геоморфология. 2001. № 4. С. 66-74.

6. Николаева С.Б. Свидетельства сейсмических событий на побережье Мурмана в позднеледниковье и голоцене (северо-восток Балтийского щита) // Известия РГО. 2013. Т. 145. Вып. 4. С. 53-65.

7. Никонов А.А. Развитие рельефа и палеогеография антропогена на западе Кольского полуострова. М-Л. Изд-во: Наука. 1964. 181с.

8. Никонов А.А., Шварев С.В., Николаева С.Б., Зыков Д.С., Флейфель Л.Д., Родкин М.В., Королева А.О. Три активные сейсмотектонические зоны высшего ранга на севере Европейской части России: прогрессрепорт // Проблемы тектоники континентов и океанов. T. 2. Материалы LI Тектонического совещания. М. Изд-во: ГЕОС. 2019. С. 86-92.

9. Родкин М.В., Никонов А.А., Шварев С.В. Оценка величин сейсмических воздействий по нарушениям и смещениям в скальных массивах // Геодинамика и тектонофизика. Вып. 3. 2012. С. 203-237. https://doi.org/10.5800/GT-2012-3-3-0072.

10. Kukkonen I.T., Olesen O., Ask M.V.S. Postglacial Faults in Fennoscandia: Targets for scientific drilling. GFF 132. 2010. P. 71-81. Doi: 10.1080/11035891003692934.

11. Lukashov A.D. Paleoseismotectonics in the northern part of Lake Onega (Zaonezhskij peninsula, Russian Karelia). Geol. Survey of Finland. Nuclear Waste Disposal Research Peport YST-90. Espoo. 1995. 36 p.

12. McCalpin, J.P. (Ed.), Paleoseismology, 2nd ed. Academic Press, (International Series, 95) Amsterdam-London. 2009. $615 \mathrm{p}$.

13. Michetti A.M., Audemard F., Azuma T. Intensity scale ESI-2007: Memorie descriptive della carta geologica d'Italia, Rome: APAT. 2007. 74 p.

14. Morner N.-A. Paleoseismicity of Sweden: a novel paradigm. Stockholm: P\&G-unit, tockholm Univ. 2003. 320 p.

15. Nikolaeva S.B. Disastrous Earthquakes in the Vicinites of the Town of Murmansk:Paleoseismological and Geological Evidence // Journal of Volcanology and Seismology. 2008. V. 2. No 3. P. 189-198. Doi: $10.1134 / \mathrm{S} 0742046308030068$

16. Shvarev S.V. Morphotectonics and exogenous processes of the Kola Peninsula // Practical Geography and XXI Century Challenges. International Geographical Union Thematic Conference dedicated to the Centennial of the Institute of Geography of the Russian Academy of Sciences, 4-6 June 2018. Moscow. Conference Book, Moscow. 2018. P. 598-604. 